\title{
LA AFECTACIÓN OCULAR TUMORAL DEL PINTOR Y ESCULTOR RIK WOUTERS (1882-1916)
}

\author{
MIR-FULLANA F ${ }^{1}$
}

Nació en el año 1882 en la ciudad belga de Malines y comenzó su formación artística a los doce años trabajando la madera en el taller de su padre que era fabricante de muebles. En el año 1897 se inscribió en la Academia de aquella ciudad realizando estudios de escultura hasta 1901 a pesar que en 1900 también se había inscrito en la Academia de Bruselas $(1,2)$.

A los veintidós años encontró a Nel, modelo de diferentes artistas y que se convertiría en su mujer y musa a la que nunca se cansaría de representar (3). Tras unos años de penurias económicas, Rik ganó un segundo premio en el concurso Godecharles con la escultura Rêverie. Se reinscribió en la Academie Royale des Beaux-Arts de Bruselas para prepararse para el premio de Roma. Su mujer enfermó de tuberculosis y se instalaron en el campo cerca de Boitsfort donde Wouters realizó los primeros estudios de pintura y de luminosidad utilizando colores claros sobre cartón... porque las telas eran demasiado caras.

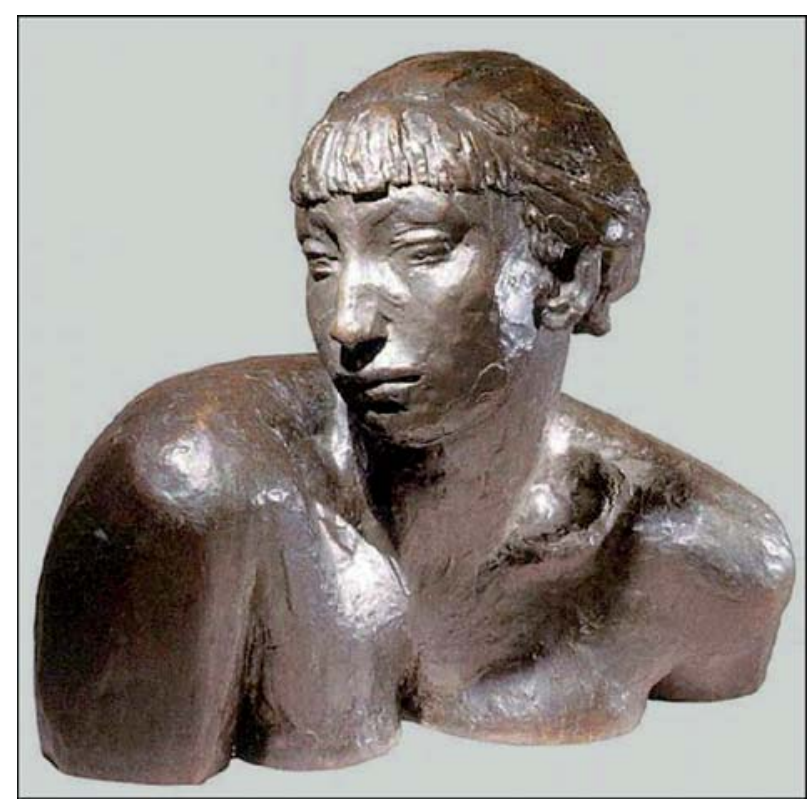

Contemplación Belgian Art Research Institute (1911).
En 1908 su reputación como escultor era notable siendo invitado a diferentes Salons y recibiendo un subsidio estatal de quinientos francos. Conoció a Simon Lévy, gran admirador de Cezanne y Van Gogh, con el que mantendría una correspondencia continuada. En 1912 contactó con Georges Giroux que le suministró todo el material que necesitaba y dándole una paga regular a cambio de la mitad del montante de la venta de sus obras. Gracias a aquella relativa estabilidad económica, Wouters inició un período de gran productividad realizando unas sesenta telas en aquel año. Viajó a París donde descubrió a los Impresionistas, especialmente a Cezanne, aumentando la cromaticidad de sus pinturas. Luego viajó a Colonia donde visitó diversas exposiciones admirando de forma especial la obra de Van Gogh (4). Su consagración como pintor llegó en 1914 cuando la galería de Georges Giroux le dedicó una exposición individual (5).

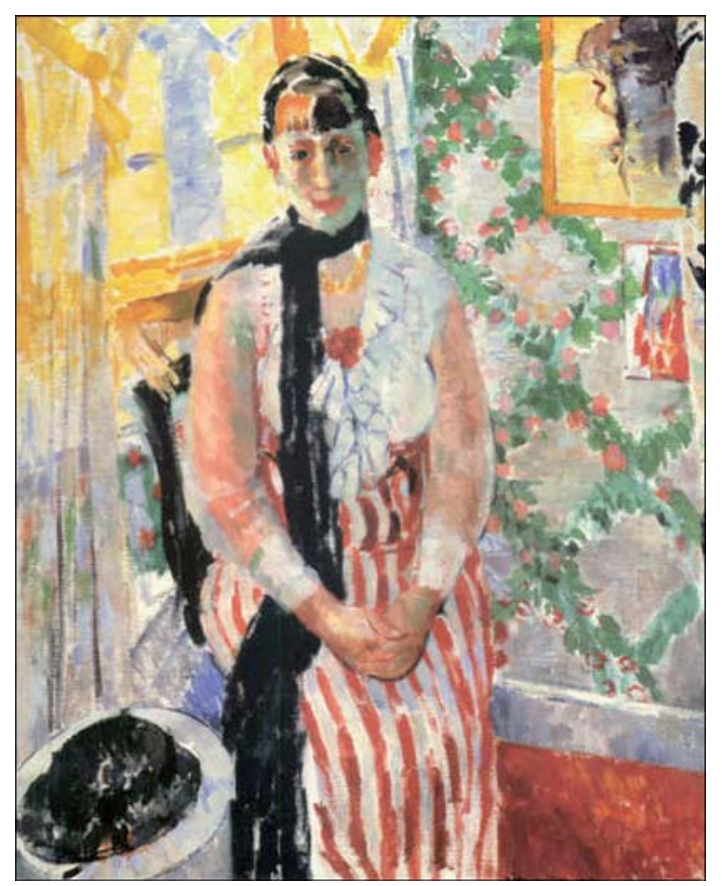

Mme. Wouters (óleo, tela) (1912).

\footnotetext{
1 Oftalmólogo.

E-mail: Fmir@mutuabalear.es
} 


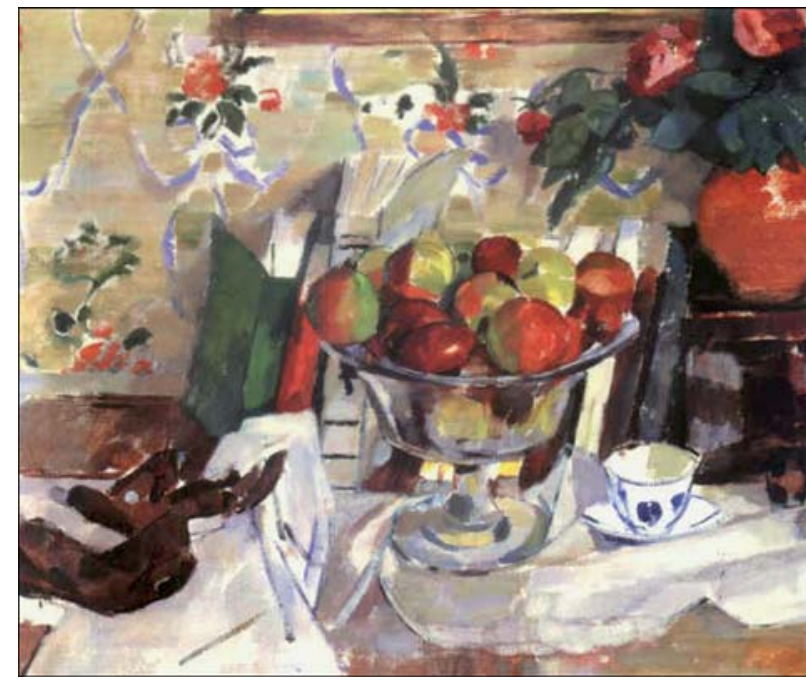

Copa de frutas, óleo (1913).

Pero cuando uno nace con mala suerte nada puede hacerse. Cuando estalló la I Guerra Mundial, Wouters fue movilizado el 31 de julio de 1914 y enviado al frente donde estuvo más de seis semanas: Liège, Lierre y Haasdonck. Su mujer abandonó Bélgica refugiándose en Holanda entonces país neutral.

Fue en aquella época bélica que Rik empezó a quejarse de intensos dolores de cabeza. El 19 de octubre de 1914 fue recluido en el campo de internamiento holandés de Amersfoort y más tarde en el de Zeist donde amigos belgas y holandeses intercedieron a su favor ante las autoridades logrando que su mujer pudiera visitarlo de vez en cuando suministrándole papel y colores con los que pudo realizar numerosos dibujos y acuarelas. Su salud se deterioró rápidamente siendo necesario practicarle varias intervenciones. A principios de 1915 y gracias a Emile Verhaeren, obtuvo el permiso para salir de día volviendo al campo solo para pernoctar. Acudía al Hospital Militar de Utrecht para las curas conservando el optimismo pese a su situación y a las operaciones. Las simpatías que despertaba el pintor eran muchas y el Sr. y la Sra. Eppo Harkema se hicieron cargo de todos los gastos médicos y los de un apartamento en Amsterdam junto a un canal muy animado donde se instaló con su mujer en junio de 1915 una vez conseguida la libertad condicional.

Al fin, el mes de julio de aquel mismo año los médicos hicieron un diagnóstico de certeza a su proceso patológico: un cáncer de maxilar, muy probablemente un sarcoma, tumoración de gran malignidad que le ocasionaba intensos dolores haciendo

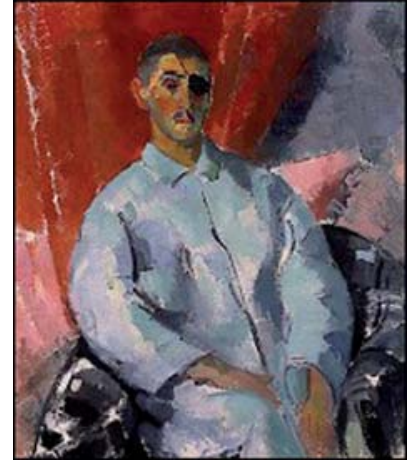

Autorretrato con venda negra (1915).

que sus sesiones de pintura fueran cada vez más penosas. Pese a ello, las obras de aquella época son explosivas y de una intensa luminosidad.

Ya en Amsterdam, la lesión cancerosa se había extendido a la órbita ocular y en una nueva intervención quirúrgica no hubo más alternativa que realizar la enucleación del globo ocular y la exéresis quirúrgica de buena parte del hueso de la órbita y del maxilar. A partir de aquella operación tan cruenta llevaba una venda negra para disimular las alteraciones faciales y aún así tuvo el humor de hacerse el autorretrato.

A pesar de todas las desgracias, Rik continuó pintando para preparar su próxima exposición en el Stedelijk Museum de Amsterdam a principios de 1916. El 5 de abril de aquel año ingresó en el Hospital del Prinsengracht para una nueva intervención. Los últimos meses de su existencia fueron de sufrimientos terribles muriendo el mes de julio de aquel mismo año.

Durante muchos años, Rik Wouters fue considerado por muchos como un simple plagiador de Cezanne hasta que el tiempo lo colocó en el lugar que le correspondía: uno de los mejores artistas belgas, uno de los mejores pintores coloristas, aparte de un excelente escultor y todo ello realizado en el corto espacio de diez años ya que solamente tenía treinta y tres años cuando murió.

\section{BIBLIOGRAFÍA}

1. Dellen AJ. Rik Wouters. Amberes: De Sikkel, 1948.

2. Devriese PP. Rik Wouters. Amberes: Pandora, 1994.

3. Wouters N. La vie de Rik Wouters à travers son oeuvre. Bruselas: Ed Lumière, 1944.

4. Bertrand O. Jalons d'une vie. Amberes: Pandora, 1994.

5. Bertrand O. Rik Wouters, les peintures, catalogue raisonné. Amberes: Pandora, 1995. 